\title{
Museu de ciência, divulgação científica e hegemonia
}

\section{José Mauro Matheus Loureiro}

Doutor em ciência da informação. Professor da Universidade do Rio de Janeiro.

E-mail: jmmloureiro@hotmail.com

\section{Resumo}

Análise do museu de ciência público como campo informacional, considerando as condições de produção e disseminação da informação/objeto musealizado nas exposições museais. Estuda a presença de uma ação hegemônica, conforme desenvolvida conceitualmente na obra de Gramsci, nas representações da ciência erigidas nos espaços museológicos científicos.

\section{Palavras-chave}

Museu de ciência; Divulgação científica; Informação; Hegemonia.

\section{Museum of science, scientific dissemination and hegemony}

\begin{abstract}
This is an analysis of public scientific museum as informational field, taking into consideration the conditions of production and dissemination of information/museum object. It investigates the articulation of Hegemony action, as developed by Gramsci, in the representations of science presented on the scientific museum exhibition.
\end{abstract}

\section{Keywords}

Science museum; Scientific dissemination; Information; Hegemony.

\section{INTRODUÇÃO}

A opção por pesquisar o conceito de hegemonia, tal como postulado por Gramsci, nas representações da informação geradas e transferidas nas exposições dos museus científicos públicos brasileiros, é norteada pela fundamentalidade de que se reveste a representação nas ações voltadas à construção, gestão e transferência da informação no ambiente expositivo museológico científico e seu uso social. Somam-se a isso a carência, o impasse e as divergências nas pouco numerosas reflexões teórico-conceituais dirigidas ao fenômeno informacional no interior dos espaços museológicos científicos públicos brasileiros, bem como a inexistência de pesquisas, concepções instrumentais e critérios teóricos relativos às questões pertinentes à representação da informação museológica no horizonte expositivo.

\section{MUSEU DE CIÊNCIA E EXPOSIÇÃO MUSEOLÓGICA}

O fenômeno museu configura-se espaço institucionalizado de memória, o qual se inter-relaciona com o indivíduo e a sociedade por meio do processamento e exposição dos bens culturais concretos e simbólicos que originam o patrimônio cultural. Assim considerando, o fenômeno museológico resgataria para o indivíduo o passado, de modo a prover um campo de significações que permita a ele e à sociedade uma contínua redefinição de sua experiência histórica e sociocultural. Não importando sua tipologia, o museu, enquanto espaço de memória social, vincula-se sempre à criação de princípios de identidade por meio de instrumentalizações técnicas e teóricas exercidas sobre os elementos culturais e naturais com que, ao menos em tese, indivíduo e sociedade se identificam e/ou concebem como próprios.

O museu de ciência contemporâneo tem sua origem no colecionismo praticado durante os séculos XV e XVI, na sistematização das coleções promovida nos "gabinetes de curiosidades”, no contexto da ascensão da burguesia como classe hegemônica ao poder, no imperialismo e nas transformações científicas e ideológicas do século XIX. De sua gênese aos dias atuais, a instituição museológica científica percorreria um extenso caminho onde se teriam plasmado e transformado sua identidade 


\section{Museu de ciência, divulgação cientifica e hegemonia}

e suas funções, de acordo com os contextos sociopolíticos e culturais em que se encontrava inserida. Não obstante as modificações sofridas por tal espaço em seu percurso no tempo, muitas de suas características primordiais permanecem até a atualidade delineando seu perfil e suas funções.

Especificamente no caso dos museus científicos brasileiros, estes foram criados no século XIX e consolidaram-se como tal entre os anos de 1870 e 1930, ciclo denominado por Schwarcz (1989, p. 27) de "A era dos museus no Brasil”.

Até então dominado pelos pesquisadores estrangeiros preocupados em classificar e coletar elementos naturais e objetos da cultura material, o horizonte intelectual brasileiro, a partir da década de 1870, foi modificado pela adoção de novas perspectivas filosóficas e políticas que transformaram "(...) costumes, padrões e visões" e trouxeram "(...) uma perspectiva pessimista na análise da situação nacional” (Schwarcz, 1989, p. 27). Positivismo, naturalismo e evolucionismo, acrescidos de influências do romantismo em suas reflexões acerca da "cultura nacional” em oposição aos aspectos coloniais, permeiam o universo científico de então. Os principais museus científicos brasileiros à época - Museu Nacional, Museu Paulista, Museu Emílio Goeldi -, além de partícipes deste processo científico local, “(...) trazem consigo questões, formas e especificidades que se remetem à lógica própria deste tipo sui generis de instituição" (Schwarcz, 1989, p. 28).

Embora os limites de suas fronteiras sejam tênues, oficialmente os museus científicos são classificados pelo International Council of Museums (Icom/Unesco) em museus de história natural e museus de ciência e técnica. Tal tipologia mostra-se simplificadora, ao desconhecer a interpenetração dos territórios temáticos dos museus científicos e também seu intercruzamento com museus de outra natureza, como, por exemplo, os de história. Esta rubrica classificatória institucional oculta uma diversificada tipologia de museus científicos que se caracterizam por sua natureza e objetivos, muito embora possamos perceber uma interpenetração entre os vários tipos de museus científicos existentes.

A partir da década de 60 do século XX, dois novos conceitos se incorporaram às reflexões acerca do universo das instituições museológicas científicas: centros de ciência (science centers) e science centrum.

Os primeiros, surgidos nos Estados Unidos no período da Guerra Fria, são entendidos como "(...) uma nova concepção de museu” (Gil, 1988, p. 73), foram criados para difundir a ciência e os produtos tecnológicos dela derivados utilizando meios de comunicação e exposições interativas, estruturadas o mais próximo possível do método científico. Encontram-se ausentes de tais instituições os objetos pertencentes ao passado científico e o caráter histórico e sociocultural do desenvolvimento da ciência e da tecnologia. Dessa forma, os museus científicos, ditos tradicionais, diferenciam-se dos centros de ciência "(...) na indole de suas exibições e seu potencial educativo" (Gil, 1988, p. 87), compartilhando, entretanto, os mesmos objetivos quanto "(...) a fomentar a educação científica e técnica, pelo seu valor cultural intrínseco e pelo que ela representa como condicionadora das sociedades modernas" (Gil, 1988, p. 87).

Os science centrum, noção incorporada em passado recente às reflexões sobre instituições científicas nos Estados Unidos, distinguem-se como instituições nas quais características dos museus científicos tradicionais e dos centros de ciência são instrumentalizadas em um só espaço.

Embora funções e papéis dos museus científicos e dos centros de ciência venham sendo explorados, a literatura acerca da instituição em apreço, em sua maior parte, tende a fazer referências ao museu de ciência e aos centros de ciência como fenômeno único, tornando por vezes dificultosa a tarefa de delimitação de seus territórios. Acreditamos, em face dos autores consultados, na tendência à interpenetração de ambos os espaços como nos denominados science centrum.

Contudo, consideramos que o museu de ciência se diferencia do centro de ciência em virtude de sua configuração como instituição voltada à preservação, gestão e difusão da história, produtos e influências socioculturais da ciência. Nesse sentido, o museu de ciência configura-se ainda, principalmente por meio da exposição museológica, como instrumento de divulgação científica.

Prática essencial e determinante do fenômeno museu, a exposição museológica caracteriza-se como elemento essencial da inter-relação museu/sociedade por meio do qual - através de aparatos teóricos e técnicos empreende-se a construção de representações.

Fenômeno de constituição plural, complexa e em permanente transformação diante de contextos socioeconômicos e culturais, a exposição museológica oferece inúmeras possibilidades interpretativas de sua realidade substantiva. Se é possível detectar modelos que tangenciam o universal, é possível também encontrar 
contextos singulares que afloram com ações criativas que perseguem uma interpretação mais criativa da realidade, do passado e do presente. As bases teóricas e operacionais que incidem sobre o universo expositivo museológico configuram-no a partir de pressupostos comunicacionais, educacionais e de entretenimento, entre outros. Diante das citadas caracterizações e mesmo de muitas outras, não é paradoxal acolher o pressuposto da exposição museológica como totalidade erigida a partir de representações que articulam o discurso museológico destinado ao social.

\section{DIVULGAÇÃO CIENTÍFICA}

Para abordarmos a divulgação científica, é importante localizá-la antes e, ainda que sucintamente, no contexto da comunicação científica, que se configura uma das mais expressivas especialidades da ciência da informação e no interior da qual se vêm produzindo, atualmente, inúmeras reflexões. Estas versam sobre a geração e transferência da informação científica, como também sobre a participação da sociedade como um todo em tais processos. A denominação comunicação científica foi criada na década de 40 por John Bernal, a fim de expressar "(...) o amplo processo de geração e transferência de informação científica” (Christovão, Braga, 1997, p. 40) entre pesquisadores.

No começo dos anos 60, Garvey \& Griffith (respectivamente, 1979, 1980) desenvolveram um modelo do processo de comunicação científica no qual predominava uma característica linear. Sob a perspectiva de ambos os autores, a comunicação científica compreende as ações vinculadas à produção, disseminação e uso da informação, desde a concepção que origina a pesquisa científica, até sua aprovação como integrante do corpus do conhecimento científico. Dessa maneira, esse processo comunicacional tem como emissor o próprio gerador do conhecimento científico - pesquisador ou cientista -, e sua transferência ocorre por canais heterogêneos de comunicação, classificados como formais e informais. Nos canais de comunicação formal, a informação é balizada por regras, procedimentos e avaliações mais rigorosos, para transmissão por meios de comunicação especializados, como periódicos - o mais utilizado e valorizado -, livros, monografias e obras de referência. Nos canais de comunicação informal, a informação, enquanto proposta de pesquisa, é apresentada intrapares pelo cientista/ pesquisador e vai gradualmente obedecendo a procedimentos de formalização, integração e avaliação. Destinada à audiência restrita, é por meio da comunicação informal que o cientista/pesquisador busca entre seus pares críticas, sugestões e apoio iniciais para o seu empreendimento científico.

Esta abordagem à comunicação científica teve continuidade por parte, principalmente, de Griffith, Price e Small, que desenvolveram pesquisas bibliométricas cujas fontes de dados eram os periódicos científicos, considerados o principal veículo de comunicação da ciência.

Na década de 70, Christovão \& Braga (1997, p. 41) apresentam proposta de redimensionamento do modelo originalmente apresentado por Garvey e Griffith (1979) a partir de uma "(...) concepção não-linear e complementando a categorização de seus domínios”. No início dos anos 80 , Christovão (1983, p. 10, 41-42) desenvolve um modelo de comunicação científica no qual distingue os processos de geração e transferência da informação considerando os “(...) países periféricos e centrais, questionando, portanto, a universalidade e neutralidade do processo de comunicação científica". Tal modelo tornou-se, também, o alicerce para uma nova abordagem à comunicação científica, a qual passou

“(...) a incorporar os processos de divulgação científica. Os temas aí desenvolvidos, via atividades de ensino e pesquisa, passaram a contemplar então todo o espectro de difusão (como no original) da informação, termo este mais abrangente que engloba tanto a disseminação (entre pares), quanto a divulgação (público mais leigo) da informação".

Analisando o ato de fazer chegar ao grande público o conhecimento científico, Hernández Cañadas (1987, p. 25), adverte quanto à controvérsia e ao uso indiscriminado na literatura referentes às designações utilizadas na classificação de tal empreendimento. Os termos difusão, disseminação e divulgação científicas são, muitas vezes, utilizados sem rigor conceitual. Esclarece a autora que a expressão difusão científica possui fronteiras abrangentes, designando "(...) todo e qualquer processo ou recurso utilizado para a veiculação de informações científicas e tecnológicas". De acordo com o público a que se destina e a linguagem empregada, a difusão científica subdivide-se em disseminação científica, difusão para especialistas e divulgação científica voltada para a circulação de informação em ciência e tecnologia para o público em geral. Assim, a difusão científica engloba a divulgação e a disseminação científicas.

A disseminação científica possui dois segmentos diferenciados: a disseminação intrapares e a disseminação extrapares. A primeira compreende o fluxo informacional em ciência e tecnologia entre especialistas 


\section{Museu de ciência, divulgação científica e hegemonia}

de uma mesma área do saber e áreas afins, e "(...) caracteriza-se por: (1) público especializado; (2) conteúdo especifico; (3) código fechado" (Bueno, 1985, p. 1421. 1422). A disseminação extrapares está voltada à propagação da informação científica e tecnológica, visando a especialistas de outras áreas do conhecimento. O público-alvo é ainda formado por especialistas, embora de áreas diferenciadas, e seu conteúdo apresenta interesse para campos heterogêneos "(...) de certa forma constituindose em uma abordagem multidisciplinar".

Também denominada vulgarização ou popularização da ciência, a divulgação científica constitui-se no emprego de técnicas de recodificação de linguagem da informação científica e tecnológica objetivando atingir o público em geral e utilizando diferentes meios de comunicação de massa. Gonzalez (1992, p. 19) concebe a divulgação científica como a "(...) comunicação entre ciência e sociedade", sublinhando que, em tal processo, o fundamental reside em comunicar em linguagem acessível "(...) os fatos e princípios da ciência”. Muitas vezes entendida restritiva e erroneamente como transmissão de informação científica e tecnológica através da imprensa, isto é, enquanto jornalismo científico, a divulgação científica, conforme Bueno, acima citado, abrange

“(...) os jornais e revistas, mas também os livros didáticos, as aulas de ciência do $2^{\circ}$ grau, os cursos de extensão para nãoespecialistas, as estórias em quadrinhos, os suplementos infantis, muitos dos folhetos utilizados na prática de extensão rural ou em campanhas de educação voltadas, por exemplo, para as áreas de higiene e saúde, os fascículos produzidos por grandes editoras, documentários, programas especiais de rádio e televisão etc.".

A prática da divulgação científica, segundo Gonzalez (1992, p. 19), é apenas uma relativa democratização do conhecimento científico, que traz em seu bojo a reiteração das práticas científicas, legitimando e reforçando o perfil ideológico da ciência. Dessa maneira, seria ilusório tomar a divulgação científica unicamente como processo que torna factível o acesso do público em geral à informação em ciência e tecnologia. Ramos (1992, p. 35), por seu turno, sublinha que a divulgação científica não se mostra uma representação da ciência, mas instituinte, no âmbito dos signos e do imaginário social, da cientificidade. Enquanto a ciência se apresenta aproximativa, provisória e passível de testes de verificação, a divulgação científica se ancora na eficácia e na autoridade impondo uma visão de mundo monológica.
Em face do exposto, acreditamos que os museus científicos constituir-se-iam espaços de divulgação científica, tendo em vista buscarem "(...) transferir aos nãoiniciados informações especializadas de natureza científica $e$ tecnológica" (Bueno, 1985, p. 1422) valendo-se da recodificação da linguagem semântica e não-semântica - instrumentos e/ou produtos científicos e tecnológicos tornados objetos musealizados. A instrumentalização e ênfase no objeto musealizado constituem os mais expressivos elementos que diferenciam a instituição museológica dos demais meios de divulgação científica. As críticas endereçadas, nos parágrafos precedentes, ao cenário da divulgação científica nos diversos veículos utilizados para tal fim, podem ser estendidas também ao espaço museológico científico com alguns acréscimos, dadas suas peculiaridades.

\section{HEGEMONIA}

A obra de Gramsci se distingue, de acordo com Châtelet et alii (1990, p. 78), por conseguir unir fidelidade e inovação às abordagens acerca do econômico e do ideológico-político no universo marxiano. Especificamente no caso do conceito de hegemonia, este mostrase instrumento privilegiado de análise das várias instâncias da sociedade.

Inicialmente empregado por Lênin com relação à função dirigente da classe operária na "Revolução DemocráticoBurguesa" em 1905, o conceito de hegemonia foi, mais tarde, reelaborado por Gramsci (1991, p. 28), que o configurou como processo permeado pelo consenso e a orientação cultural nos quais não prevalecem o uso da coerção, da força ou da ingerência "(...) legislativa e estatal ou policial". Esclarece, ainda, a instância a partir da qual se dá o exercício da hegemonia, ao salientar a existência de dois patamares superestruturais: "sociedade civil", conjunto formado pelos organismos denominados privados, e "sociedade política ou Estado". Ambos “(...) correspondem à função de 'hegemonia' que o grupo dominante exerce em toda sociedade e àquela de 'dominio direto' ou de comando que se expressa no Estado e no governo 'jurídico'. Tais funções configuram-se organizativas e conectivas" (Gramsci, 1979, p. 10-11).

O processo de hegemonia - não se restringindo aos limites da nação, mas alcançando o âmbito internacional caracteriza-se obrigatoriamente por uma ação pedagógica possuidora, em seu princípio teórico-prático, de valor gnoseológico. Isso porque a concretização de um “(...) aparato hegemônico, enquanto cria um novo terreno ideológico, determina uma reforma das consciências e dos métodos de 
conhecimento, é um fato de conhecimento, um fato filosófico" (Gramsci, 1979, p. 52).

A capacidade de conhecimento crítico de si mesmo é alcançada a partir de entrechoques de "hegemonias" diferenciadas inicialmente no campo da ética e, posteriormente, no da política, "(...) atingindo, finalmente, uma elaboração superior da própria concepção do real" (Gramsci, 1979, p. 21). Dessa forma, o progresso do conceito político de hegemonia não se circunscreve somente ao aperfeiçoamento político-prático, mas significa, ainda, um avanço no terreno filosófico, já que envolve "(...) uma unidade intelectual e uma ética adequadas a uma concepção do real que superou o senso comum e tornouse crítica, mesmo que dentro dos limites ainda restritos" (Gramsci, 1979, p. 21).

Discordando do economicismo, não reconhece serem as "(...) expressões de vontade, de ação e de iniciativa política e intelectual" oriundas das necessidades econômicas. A concretização da hegemonia prefigura considerar que

"(...) se deve levar em conta os interesses e as tendências dos grupos sobre os quais a hegemonia será exercida; que se forme certo equilibrio de compromisso, isto é, que o grupo dirigente faça sacrifícios de ordem econômico-corporativa. Mas também é indubitável que os sacrifícios e o compromisso não se relacionam com o essencial, pois se a hegemonia é ético-política também é econômica: não pode deixar de se fundamentar na função decisiva que o grupo dirigente exerce no núcleo decisivo da atividade econômica" (Gramsci, 1979, p. 33).

A origem teórica do conceito de hegemonia, repousando em "(...) uma análise comparativa dos tipos de tomada de poder pela burguesia, uma teoria e uma prática da revolução" (Buci-Glucksmann, 1990, p. 69-70), foi, dentre os conceitos propostos e refletidos por Gramsci, o que sofreu maiores transformações. Inicialmente vinculado a uma “(...) estratégia alternativa do proletariado (hegemonia do proletariado)", mais tarde, pelo desenvolvimento do conceito de aparelho de hegemonia, passou a abarcar as ações da classe dominante e progressivamente, ainda, as estruturas do Estado. A hegemonia não se restringe somente ao momento cultural e não encontra seu fim nas ações dos intelectuais enquanto elo relacional entre base e superestrutura.

Embora compreenda articulações dirigidas para a manutenção do "(...) consenso das massas para uma política das classes" (Buci-Glucksmann, 1990, p. 81), a hegemonia não deve ser circunscrita e/ou confundida com a noção de 'ideologia dominante', tal como desenvolvida na obra marxiana, nem tampouco com os 'mecanismos de legitimidade’ presentes nas proposições weberianas.

O conceito de hegemonia no pensamento gramsciano é concebido enquanto direção e domínio, isto é, “(...) como conquista, através da persuasão, do consenso" e forma de oposição e luta contra as classes oponentes. A hegemonia atua não apenas no âmbito do econômico e político da sociedade, "(...) mas também sobre o modo de pensar, sobre as orientações ideológicas e inclusive sobre o modo de conhecer". As classes dominantes impõem sua concepção de mundo, permeada pela ideologia que atende à sua função histórica e a seus interesses, às classes dominadas. A concepção de mundo das primeiras atinge as classes subalternas por vários meios "(...) através dos quais a classe dominante constrói a própria influência ideal, a própria capacidade de plasmar as consciências de toda a coletividade, a própria hegemonia".

Em meio às classes dominadas, a concepção de mundo dominante é instrumentalizada como elemento de manutenção da uniformidade ideológica do bloco social, que se apresentaria heterogêneo e atravessado por contradições de classe. No universo gramsciano, portanto, a hegemonia é "(...) a capacidade de unificar através da ideologia e de conservar unido um bloco social", não se restringindo ao aspecto político, mas compreendendo “(...) um fato cultural, moral, de concepção do mundo”.

A partir de tais inferências, Gruppi (1978, p. 3, 58, 68, $70,73,82)$ interpreta o conceito de hegemonia enquanto processo no qual amplas parcelas das camadas populares, a despeito de interesses contrários aos da classe ou fração de classe dominante, "(...) são basicamente subordinadas" por ausência de concepção de mundo e cultura próprias, absorvendo "(...) a cultura das classes dominantes de maneira heterogênea, desorgani-zada, passiva”.

Conforme Tosel \& Gramsci, refletindo sobre as modificações ocorridas nas relações economia/política e massas/Estado, investiga os procedimentos por meio dos quais "(...) o Estado aumenta seu espaço no social (constituição de uma rede de aparelhos que executam funções sociais)" alcançando o consenso nos quadros burgueses. Assim, a hegemonia se caracteriza como categoria, concomitantemente analítico-descritiva e estratégica.

A dimensão filosófica e teórica da categoria de hegemonia pode ser entendida quando se considera que a mesma enseja e permite "(...) a elevação das massas, a formação de um novo senso comum, a elaboração de uma nova racionalidade social" (Tosel, 1979, p. 78-79). A categoria 
de hegemonia em Gramsci modifica, mas não suprime, os postulados teóricos da ditadura do proletariado tal como desenvolvida por Lênin. Pela via da hegemonia, a ditadura do proletariado constitui dominação sob a égide do consenso e o emprego da coerção é ínfimo à medida que esta não se mantém por longo tempo.

Na interpretação de Carnoy (1988, p. 95), o conceito de hegemonia em Gramsci apresenta duas vertentes essenciais. $\mathrm{Na}$ primeira, denota um processo cuja ocorrência se dá na sociedade civil, por meio do qual “(...) parte da classe dominante exerce o controle, através de sua liderança moral e intelectual, sobre outras frações aliadas da classe dominante". Neste caso, a fração de classe dominante não inflige sua ideologia aos aliados, mas representa e articula procedimentos pedagógicos e alterações formadas a partir de elementos consensuais aos interesses das demais frações de classe aliadas. $\mathrm{Na}$ segunda vertente, a classe dominante intrumentaliza com exxito "(...) sua liderança politica, moral e intelectual para impor sua visão de mundo como inteiramente abrangente e universal, e para moldar os interesses e as necessidades dos grupos subordinados".

Chauí (1982, p. 18-19), mencionando a profunda conexão dos conceitos de sociedade civil, "(...) organização e regulamentação das instituições que constituem a base do Estado”, sociedade política, “(...) passagem da necessidade (econômica) para a liberdade (política), da força para o consenso" e hegemonia, indica que esta última se concretiza na sociedade civil como direção cultural e na sociedade política enquanto direção política: “(...) é a criação da 'vontade coletiva' para uma nova direção politica e também a 'reforma intelectual e moral' para uma nova direção cultural".

Distinguindo-se do governo - como instituição política, que em algumas circunstâncias utiliza-se da força - e da ideologia enquanto "(...) sistema abstrato e invertido de representações, normas, valores e crenças dominantes”, a hegemonia não se configura um modo de

“(...) controle sociopolitico nem de manipulação ou doutrinação, mas uma direção geral (política e cultural) da sociedade, um conjunto articulado de práticas, idéias, significações e valores que se confirmam uns aos outros e constituem o sentido global da realidade para todos os membros de uma sociedade, sentido experimentado como absoluto, único e irrefutável porque interiorizado e invisivel como o ar que se respira. Sob essa perspectiva, hegemonia é sinônimo de cultura em sentido amplo e sobretudo de cultura em sociedade de classes" Chauí (1982, p. 19).
O conceito de hegemonia se mostraria uma expressiva teoria que enseja uma contribuição interpretativa fundamental às investigações acerca dos fenômenos essenciais aos heterogêneos e complexos domínios do social. Ensejando refletir sobre a estrutura econômica, a organização política, o pensar, o conhecer e a ideologia, o conceito de hegemonia permite-nos articular abordagens nas quais os quadros históricos, político-jurídicos, socioculturais e econômicos se forjam e interpenetram.

De acordo com o conceito gramsciano de hegemonia, a classe dominante não depende única e tão-somente do poder do Estado ou de seu próprio poder econômico, mas se utiliza de um conjunto de relações, experiências e atividades para promover, junto às classes subalternas, seu sistema de crenças. Nesse sentido, o museu público, organizado e dirigido a partir do Estado, constituir-se-ia espaço onde as classes dominantes buscariam persuadir, naturalizar e fazer com que as classes dominadas compartilhassem seus valores morais, sociais e culturais. Desse modo, o museu de ciência público, por meio de suas construções representacionais expositivas, ao buscar a adesão e o consenso, mostrar-se-ia, por trás de seus anteparos técnicos e científicos, locus de ações hegemônicas.

\section{CONSIDERAÇÕES GERAIS: UMA PROFANA LITURGIA HEGEMÔNICA}

Contemporaneamente, seminários, simpósios, periódicos científicos e os meios de comunicação de massa têm enfocado as modificações pelas quais as exposições permanentes dos museus de ciência vêm passando. São ressaltados os aspectos das novas formas de apresentação de suas exposições que, aliando um novo design aos aspectos lúdicos e interativos, estariam estabelecendo transformações essenciais no fenômeno museu enquanto instrumento de divulgação científica. Este contexto de inovações introduz elementos que, sem dúvida, auxiliam na assimilação dos produtos da ciência, mas instala diferenças apenas quanto à forma e participação do público. O conteúdo, a ciência, tem sua representação condicionada a um produto final, excluindo-se todas as singularidades e idiossincrasias de seu processo construtivo.

A exposição museológica dos museus de ciência públicos brasileiros apresentar-se-ia como uma totalidade na qual são dispostas representações de representações do conhecimento científico. O caráter fundamental da ciência para o desenvolvimento das forças produtivas no âmbito do horizonte capitalista e sua vinculação às 
classes dirigentes fariam com que as representações expositivas científicas presentes na maior parte dos museus de ciência públicos brasileiros estivessem substantivamente permeadas por valores e determinações de ordem histórico-cultural e político-ideológica. As representações ali divulgadas por meio das exposições constituir-se-iam de valores e determinações de perspectivas cientificistas que reiteram determinações de ordem histórico-cultural e político-ideológico das classes dominantes.

A informação enquanto ferramenta semiótica que engendra e estrutura as representações museológicas transferidas no âmbito expositivo museológico por meio dos produtos finais da ciência encontrar-se-ia permeada de valores, crenças, normas, interpretações e reflexões que circunscreveriam a divulgação científica a um sistema modelar de incorporação do pensar, do conhecer e da ideologia das classes ou frações de classe dominantes.

Assim considerando, os museus de ciência públicos brasileiros, integrando a superestrutura (sociedade civil + sociedade política ou direção cultural ou moral + aparelho de Estado), contribuiriam, por meio de suas representações expositivas, para a efetivação da hegemonia. Em sua ação no âmbito pedagógico e gnosiológico, as representações expositivas, desconhecendo e/ou mascarando a inter-relação ciência/ forças produtivas/classes ou frações de classe dominantes no seio do capitalismo, articulariam um discurso como meio de persuasão, orientação e direção cultural e ideológica.

A autoridade e a eficácia do discurso científico cristalizado na informação que integra as representações museológicas, sob o manto do binômio lazer/educação informal, universalizariam e institucionalizariam projetos culturais e ideológicos que induziriam as classes subalternas ao consenso quanto às demandas das classes ou frações de classe dominantes.

Institucionalizando sentidos, tornando periféricos e reificando todos os conhecimentos não-científicos, e criando determinismos advindos da ortodoxia científica, a sintaxe representacional das exposições museais científicas buscaria a persuasão e o consenso quanto à concepção do real e à lógica capitalista e burguesa que a preside.

As representações expositivas científicas configurar-seiam arbitrários representacionais, e por meio delas se divulgaria uma informação de caráter orientador moral, cultural e intelectual. Circunscrevendo e delimitando o território dos monólogos, tais representações não fecundariam o solo da dialogicidade, mas, ao contrário, tornar-se-iam obstáculos para uma práxis voltada a transformações reais.

A cientificidade incorporada no escopo das representações expositivas museais científicas abordadas parece encobrir as contradições da sociedade capitalista e a função histórica das classes dominadas, impedindo e/ou desarticulando novas alternativas, confrontos e estratégias destinados a promover transformações estruturais no modo de produção capitalista. A divulgação científica serviria de recurso por meio do qual as forças dominantes forjariam consciências, impedindo o surgimento de novos territórios ideológicos.

O início da reversão de tais características das exposições dos museus científicos passaria pela reformulação relacional com a esfera pública. Para tanto, faz-se necessária estratégia de rompimento com o monopólio intelectual, ideológico e cultural que regula e reveste a informação presente na natureza de suas representações. A adoção de perspectivas inter-relacionais com as várias correntes de pensamento que integram a sociedade mostrar-se-ia relevante para a ruptura dos cânones vigentes, contemplando, efetivamente, a consubstanciação senso comum/ciência.

Tal empreendimento permitiria a elaboração e construção conjunta e simultânea da interpretação do real e da construção de concepções de mundo em bases dialógicas, heterológicas e co-participativas. Ultrapassando as esferas de persuasão, direção cultural, ideológica e política e a institucionalização das práticas objetivadas no âmbito da hegemonia, promover-se-ia a construção de representações expositivas museológicas a partir de empreendimentos informacionais gerados por meio de uma práxis coletiva, emancipadora e libertadora.

Nesse sentido, a informação contida nas representações museológicas de natureza científica permitiria a transformação das exposições museológicas em espaços de interlocução e, conseqüentemente, de recriação permanente da realidade e dos condicionamentos conjunturais.

Pelo seu caráter celebrativo, evocativo e até mesmo pelo clima sacramental e mistagógico no qual é situado o leigo, as exposições museológicas científicas mostrar-seiam uma profana liturgia hegemônica. 
Sob a égide da Igreja Católica Apostólica e Romana, a liturgia compreende ato de culto público e ritualizado, no qual somente sob a presidência de um sacerdote se empreende a celebração da eucaristia. Participando toda a Igreja como sacramento da unidade, isto é, povo reunido e organizado sob a autoridade dos bispos, a liturgia sofreu, através dos tempos, inúmeras modificações quanto à sua forma ritual, linguagem e alfaias. Ao longo de todos esses séculos, contudo, os dogmas, a exigência da fé e a sua efetivação por parte da hierarquia sacerdotal jamais foram deixadas de lado.

Assim também se apresentariam as exposições museológicas científicas: ato de culto público e ritualizado à ciência, cuja celebração expositiva se encontraria a cargo dos profissionais dos museus e da ciência, que buscariam a unidade ideológica, a reunião e a organização dos dominados e excluídos por parte das classes dominantes. Tais exposições sofreriam, ainda, modificações com o passar dos anos, sem que deixassem de exigir do público a fé nos dogmas científicos e o exercício da ciência por parte de uma hierarquia acadêmica.

Acreditamos que as diferenças básicas entre as exposições museológicas tradicionais e aquelas calcadas no modelo emergente de exposição científica residam em um design mais contemporâneo, no aspecto lúdico e na interatividade que caracterizam as últimas. É importante ressaltar que tais características são, sem dúvida, da maior importância no que se refere ao papel pedagógico do museu. Entretanto, acreditamos que seria pertinente estender as críticas e observações feitas aos museus de ciência tradicionais aos demais museus de ciência públicos brasileiros, uma vez que, em todos eles, prevaleceriam a apresentação dos produtos finais da ciência e o obscurecimento da noção de processo. Em ambos os modelos permaneceriam a representação expositiva da ciência capitalista, o caráter de persuasão e o dirigismo cultural e ideológico.

Artigo aceito para publicação em 12-12-2002

\section{REFERENCIAS}

BUCI-GLUCKSMANN, Christine. Gramsci e o Estado. 2. ed. Rio de Janeiro: Paz e Terra, 1990. p. 70.

BUENO, Wilson da Costa. Jornalismo científico: conceitos e funções. Ciência e Cultura, n. 37, v. 9, p. 1420-1428, set. 1985.

CARNOY, Martin. Estado e teoria politica. 2. ed. Campinas : Papirus, 1988. p. 95.

CHÂTELET, Michel; DUHAMEL, Olivier; PISIER-KOUCHNER, Évelyne. Histórias das idéias políticas. Rio de Janeiro : Jorge Zahar, 1990. p. 78.

CHAUÍ, Marilena. Cultura e democracia: o discurso competente e outras falas. 3. ed. São Paulo : Moderna, 1982. p. 18.

CHRISTOVÃO, Heloisa Tardin. The aging of the literature of biomedical sciences in developed and underdeveloped countries. 1983. Tese [Doutorado em Ciência da Informação) - Drexel University, Philadelphia, 1983.

; BRAGA, Gilda Maria. Ciência da informação e sociologia do conhecimento científico: a intertematicidade plural. Transinformação, v. 9, n. 3, p. 33 - 45, set./dez. 1997.

GARVEY, William D. Communication: the essence of science. London : Pergamon, 1979. p. ix

GIL, Fernando Bragança. Museus de ciência: preparação do futuro, memória do passado. Colóquio ciências. Revista da Cultura Científica, n 3, p. 72-89, out. 1988.

GONZALES, Maria Iracema. A divulgação científica: uma visão de seu público leitor. 143 f. 1992. Dissertação (Mestrado em Ciência da Informação) - IBICT/UFRJ/ECO, Rio Janeiro, 1992. p. 19.

GRAMSCI, Antonio. Cartas do cárcere. 4 ed. Rio de Janeiro : Civilização Brasileira, 1991. p. 28, 33.

Os intelectuais e a organização da cultura. 3. ed. Rio de Janeiro : Civilização Brasileira, 1979. p. 10-11.

GRUPPI, Luciano. O conceito de hegemonia em Gramsci. 2. ed. Rio de Janeiro: Graal, 1978. p. 58.

HERNÁNDEZ CAÑADAS, Patrícia Liset. Os periódicos: Ciência Hoje e Ciência e Cultura e a divulgação da ciência no Brasil. 190 f. 1987. Dissertação (Mestrado em Ciência da Informação) - IBICT/UFRJ/ ECO, Rio de Janeiro, 1987. p. 25.

RAMOS, Marcos G. A questão da informação em energia nuclear: discurso, linguagem e poder. 171 f. 1992. Dissertação (Mestrado em Ciência da Informação) - IBICT/UFRJ/ECO, Rio de Janeiro, 1992. p. 35.

SCHWARCZ, Liliam K. M. O nascimento dos museus no Brasil: 1870-1910. In: MICELI, Sergio. (Org.). História das ciências sociais no Brasil. São Paulo : Vértice, 1989. v. 1. p. 27.

TOSEL, André. Hegemonia e pluralismo: a elaboração teórico-política do marxismo italiano. Encontros com a Civilização Brasileira. Rio de Janeiro, n. 13, p. 77-96, jul. 1979. 